Alonso García, María Nieves. Retos jurídico-políticos de las funciones parlamentarias y los novedosos instrumentos de participación en la democracia del Siglo XXI. Dykinson S.L. Madrid, 2019, 197 pp., ISBN 9788413242132.

http://dx.doi.org/10.18543/ed-67(2)-2019pp585-586

La editorial Dykinson ha publicado este trabajo de la profesora de Derecho Constitucional, María Nieves Alonso García, que lleva como título «Retos jurídico-políticos de las funciones parlamentarias y los novedosos instrumentos de participación en la democracia del siglo XXI». La publicación nos brinda la posibilidad de conocer la tesis doctoral elaborada por la autora y dirigida por la profesora Esther Seijas Villadangos, catedrática de Derecho Constitucional de la Universidad de León, quien, además, prologa el libro, donde señala el origen de este trabajo: «la preocupación de la autora por las pretensiones de celebrar un referéndum secesionista en Cataluña y su repercusión desestabilizadora sobre el sistema constitucional español, y más aún sobre los propios pilares dogmáticos del mismo». La prologuista también adelanta uno de los méritos de este libro, el estilo depurado y culto que hace amena su lectura.

El trabajo se estructura en introducción, tres grandes capítulos y unas reflexiones finales. Además de la bibliografía la autora nos proporciona unos útiles anexos donde recoge las fuentes legales y jurisprudenciales.

En la Introducción la profesora da cuenta de la «fatiga democrática» que vive nuestro país, que se manifiesta y trae causa, a su vez, en el deterioro que sufren nuestras bases democráticas. Por un lado la politización del Parlamento que ve difuminarse sus funciones parlamentarias y cuestionarse su representatividad. Por otro lado la preponderancia del Ejecutivo que acumula funciones y tareas del Legislativo, «como si el monopolio de la política terminará soldando los poderes que tanto costó separar», frase feliz literariamente y tan expresiva que no deja de producir gran preocupación. El trabajo utiliza un método «sincrético» al combinar análisis jurídicos y políticos.

En el Capítulo I «Parlamentarismo y crisis de la representación», a partir de un encuadre teórico, se describe la realidad de nuestro parlamentarismo y se analizan las causas que lo están arrastrando en una deriva presidencialista que se compadece mal con nuestra monarquía parlamentaria concebida sin los contrapesos de un auténtico presidencialismo. 
El Capítulo II «Lectura contemporánea de las funciones del Parlamento» profundiza en el abuso de la figura del Decreto Ley y en las maniobras gubernamentales para zafarse del control parlamentario. Tras un análisis y propuesta de reforma de nuestro sistema electoral se ahonda en la función deliberativa del Parlamento y en la buena utilización de los medios de comunicación para difundir la actividad parlamentaria. Se aboga, finalmente, por propiciar la labor integradora y ejemplarizante del Parlamento en aras de la "consolidación de una cultura constitucional».

La interacción entre derechos de representación y participación es el objeto de estudio del capítulo III «Propuestas de lege ferenda de incardinación de la participación ciudadana en la representación parlamentaria», donde después de señalar y analizar críticamente, en un estudio exhaustivo, los mecanismos de participación, se proponen nuevas vías de participación que tienen en cuenta experiencias del Derecho comparado. Muy útil para el jurista es el estudio que se hace sobre la participación de los ciudadanos en el procedimiento legislativo, en particular en el ámbito autonómico. En el apartado III de este capítulo se exponen dos interesantes experiencias del Derecho comparado: las convenciones constitucionales y el referéndum revocatorio. Por último se resaltan las posibilidades que para la democracia directa representan las nuevas tecnologías que tienen su reflejo en varias recomendaciones del Consejo de Europa y que abren el camino hacia el denominado «Parlamento abierto» fruto de la «ciudadanía electrónica».

Inmediatamente antes de las reflexiones finales, la autora nos ofrece unas propuestas de democracia parlamentaria que constituyen una interesante y valiente aportación. Para paliar la confusión que se está produciendo entre Parlamento y gobierno, e inspirándose en el modelo directoral suizo se propone un «órgano colegiado semiparitario». Aprovechándose de la irrupción de las tecnologías de información y comunicación se apuesta, una vez más, por un «Parlamento abierto» en el que se potencien las nuevas capacidades parlamentarias «en particular la capacidad de comunicación, la misión pedagógica e instructiva y la evaluadora».

En definitiva, el concienzudo trabajo de la profesora Alonso García expuesto tan ágilmente nos proporciona un instrumento de reflexión y análisis sobre «la conciliación de la democracia representativa y fórmulas de participación en la democracia representativa contemporánea» y nos ofrece interesantes propuestas, entre las que destaca la posibilidad del Parlamento ciberabierto.

Juan Luis de Diego Arias

UNED 


\title{
Alonso García, María Nieves. Retos jurídico-políticos de las fun- ciones parlamentarias y los novedosos instrumentos de partici- pación en la democracia del Siglo XXI. Dykinson S.L. Madrid, 2019, 197 pp., ISBN 9788413242132.
}

\author{
http://dx.doi.org/10.18543/ed-67(2)-2019pp585-586
}

\section{Copyright}

Estudios de Deusto es una revista de acceso abierto, lo que significa que es de libre acceso en su integridad. Se permite su lectura, la búsqueda, descarga, distribución y reutilización legal en cualquier tipo de soporte sólo para fines no comerciales, sin la previa autorización del editor o el autor, siempre que la obra original sea debidamente citada y cualquier cambio en el original esté claramente indicado

Estudios de Deusto is an Open Access journal which means that it is free for full access, reading, search, download, distribution, and lawful reuse in any medium only for non-commercial purposes, without prior permission from the Publisher or the author; provided the original work is properly cited and any changes to the original are clearly indicated. 